\title{
Applying Improved Droop Control to Hybrid Microgrid Control
}

\author{
Hyeon-Kyun Ji, Hyeong-Jun Yoo, Thai-Thanh Nguyen, and Hak-Man Kim * \\ Incheon National University \\ hmkim@inu.ac.kr
}

\begin{abstract}
Hybrid microgrid consists of $A C$ and DC grids, in which the interlinking converter is used to connect AC and DC microgrids. The droop control scheme is widely applied to hybrid microgrid control including interlinking converter because it can be used to control power in hybrid microgrid without communication. However, the existing steadystate error in conventional droop control might affect to the power quality of sensitive load. Therefore, the improved droop control scheme is proposed in this study, in which the steady-stated error is removed by using an additional PI regulator. Various simulation scenarios in term of load variations are performed in the MATLAB/Simulink environment to verify the control performance of proposed control scheme. Simulation results show that the frequency and DC voltage are controlled stably by using improved droop control scheme.
\end{abstract}

Keywords: Hybrid microgrid, AC grid, DC grid, Interlinking converter, Improved droop control

\section{Introduction}

Microgrids have been widely investigated in distribution power systems owing to their advantages such as high reliability of power supplies and low environmental impacts. In general, microgrids compose distributed energy resources (DERs) including renewable energy sources (RESs), distributed energy storage systems (ESSs), and local loads [1-3]. $\mathrm{AC}$ microgrids are well-established configurations that correspond with the conventional power systems. In AC microgrids, it is necessary to use the DC-AC or AC-DC power conversions, because there is a variety of DC loads as well as RESs that generate DC power such as photovoltaic or need a DC link to transfer power such as wind or solar farm. Therefore, DC microgrids have been introduced to eliminate these power conversions that cause the significant energy losses. DC microgrids can bring the benefits in terms of efficiency, cost, and energy losses [4-7]. However, AC microgrids are still dominant owing to the majority of the power grids being AC types. Therefore, hybrid microgrids with a link between AC and DC microgrids have become interesting in recent studies, because they can employ the advantages of both microgrids [8-10].

Hybrid microgrids can be operated in grid-connected or islanded modes. In the gridconnected mode, hybrid microgrids control power flow between hybrid microgrids and utility grid through the point of common coupling (PCC). On the other hand, in the islanded mode, hybrid microgrids control power flow between the AC and DC microgrids through an interlinking converter. The frequency in AC microgrids and DC voltage in DC microgrids are maintained stably in the acceptable ranges by the interlinking converter [11-12]. In general, the droop control scheme is widely applied for the control system of the interlinking converter, because it can be used for sharing power among different sources without communication [13-15]. However, the limitation of the droop control

* Corresponding Author 
scheme is the existing steady-state error that might affect to the power quality of the sensitive loads [16].

In this study, an improved droop control scheme is proposed to remove the steady-state error of the conventional droop control scheme. In the normal condition, the improved frequency and DC voltage droop control scheme are applied to the BESS and to the controllable DC sources, respectively. When the BESS or DC sources cannot supply sufficiently power, the interlinking converter is used to control the frequency or DC voltage. In this study, various simulation scenarios in term of load variations are performed in MATLAB/Simulink environment to test the performance of the proposed control scheme.

\section{Hybrid Microgrid Structure}

The hybrid microgrid consists of the AC grid, DC grid, and the interlinking converter that connects the AC and DC grids, as shown in Figure 1. Table 1 shows the rated power of each component in the hybrid microgrid. The $\mathrm{AC}$ grid is composed of two battery energy storage systems (BESSs), diesel generator, and variable load. Besides, the DC grid is composed of two controllable DC sources and variable load. BESSs and controllable DC sources are operated respectively based on frequency droop control and DC voltage droop control to maintain frequency and DC line voltage. The interlinking converter controls power flow between $\mathrm{AC}$ and $\mathrm{DC}$ grids, which depends on the status of power supplies in $\mathrm{AC}$ and $\mathrm{DC}$ grids.

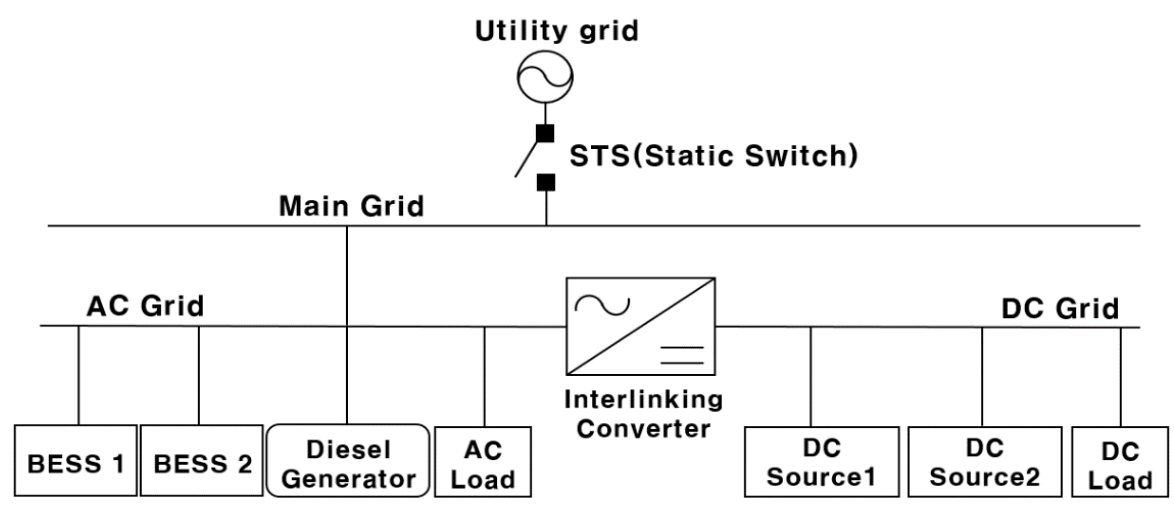

Figure 1. Structure of the Hybrid Microgrid

Table 1. Rated Power of Components in the Hybrid Microgrid

\begin{tabular}{|c|c|c|}
\hline \multicolumn{2}{|c|}{ Component } & Rated Power \\
\hline \hline \multirow{4}{*}{ AC Grid } & BESS 1 & $50 \mathrm{~kW}$ \\
\cline { 2 - 3 } & BESS 2 & $30 \mathrm{~kW}$ \\
\cline { 2 - 3 } & Variable AC Load & $100 \mathrm{~kW} \sim 180 \mathrm{~kW}$ \\
\cline { 2 - 3 } & Diesel Generator & $70 \mathrm{~kW}$ \\
\hline \multirow{4}{*}{ DC Grid } & DC Source 1 & $40 \mathrm{~kW}$ \\
\cline { 2 - 3 } & DC Source 2 & $30 \mathrm{~kW}$ \\
\cline { 2 - 3 } & Variable DC Load & $30 \mathrm{~kW} \sim 90 \mathrm{~kW}$ \\
\hline & Interlinking Converter & $40 \mathrm{~kW}$ \\
\hline
\end{tabular}




\section{Control of the Hybrid Microgrid}

\subsection{Improved Droop Control Scheme}

In general, a conventional droop control scheme is used to share power among the multiple sources without communication. The frequency and DC voltage are controlled according to P-f droop characteristic and I-V droop characteristic as given in (1) and (2). Such the conventional droop control scheme always has a steady-state error, as shown in (3) and (4).

$$
\begin{gathered}
f_{1}-f_{0}=K_{f}\left(P_{1}-P_{0}\right) \\
V_{d c, 1}-V_{d c, 0}=R_{V}\left(I_{1}-I_{0}\right) \\
\delta=f^{*}-f \\
\varepsilon=V_{d c}{ }^{*}-V_{d c}
\end{gathered}
$$

where $K_{f}$ is frequency droop characteristic, $R_{V}$ is DC voltage droop characteristic, $\delta$ and $\varepsilon$ are the steady-state errors of frequency and DC voltage, respectively.

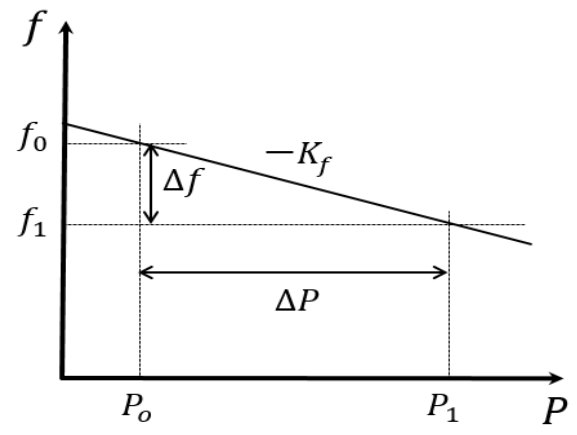

(a) Frequency

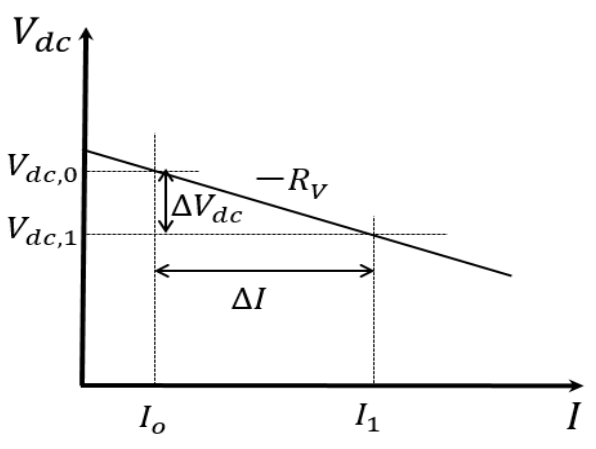

(b) DC voltage

Figure 2. The Conventional Droop Control Scheme

In this study, the improved droop control scheme is based on the conventional droop control scheme. An additional PI controller is used in the improved droop control scheme to compensate the steady-state error that occurs in the conventional droop control, as given in (5) and (6).

$$
\begin{gathered}
f^{* *}=\left\{\delta k_{p}+\delta \frac{k_{i}}{s}\right\}+f^{*}-P K_{f} \\
V_{d c}^{* *}=\left\{\varepsilon k_{p}+\varepsilon \frac{k_{i}}{s}\right\}+V_{d c}^{*}-I_{d c} R_{V}
\end{gathered}
$$

where $f^{* *}$ and $V_{d c}{ }^{* *}$ are compensated frequency and DC voltage, respectively, $k_{p}$ and $k_{i}$ are gain values of a PI controller.

\subsection{Proposed Control Scheme for BESSs and Controllable DC Sources}

Generally, the control systems of BESSs and controllable DC sources are based on vector-controller technique with inner current and outer control loops using PI regulators. The improved frequency or DC voltage droop control is applied to outer control loop as shown in Figures 3 and 4, respectively. The frequency of AC grid is controlled through the d-axis current in the BESSs. Stable frequency of AC grids and DC voltage of DC gird 
correspond to balance between power supplies and power demands, which can be achieved by using the improved droop control scheme.

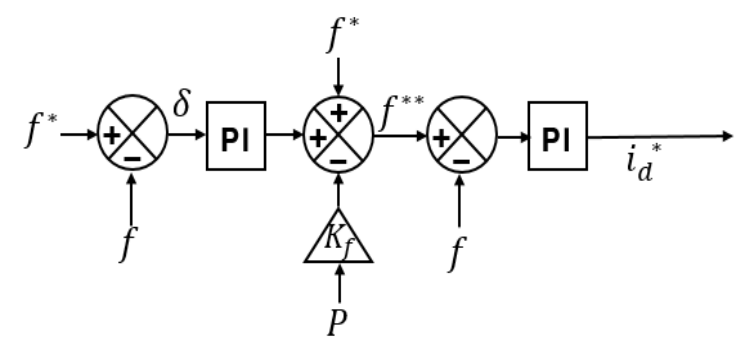

Figure 3. Improved Frequency Droop Control of the BESS

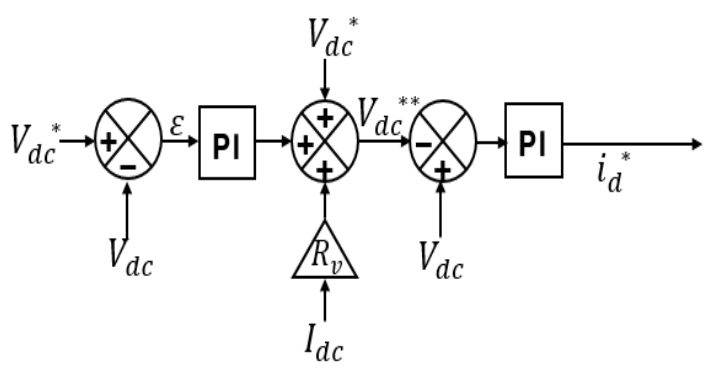

Figure 4. Improved DC Voltage Droop Control of the Controllable DC Source

\subsection{Control of the Interlinking Converter}

In this study, the interlinking converter is used to connect the AC and DC grids, which can controls the frequency of AC grid or DC voltage of DC grid. The control block diagram of the interlinking converter is shown in Figure 5. The status of power in AC and DC grids is represented by state of the hybrid microgrid that defines the control objective such as frequency or DC voltage. For example, if AC load is larger than AC power supply and the DC grid has surplus power, the power is transferred from the DC grid to the AC grid by interlinking converter using improved frequency droop control. On the other hand, if DC load is larger than DC power supply and the AC grid has surplus power, the power in AC grid is transferred to DC grid by using improved DC voltage droop control. However, if the total load of the hybrid microgrid is larger than a total power supply of the hybrid microgrid, the load in hybrid microgrid is shed to maintain stably frequency and DC voltage.

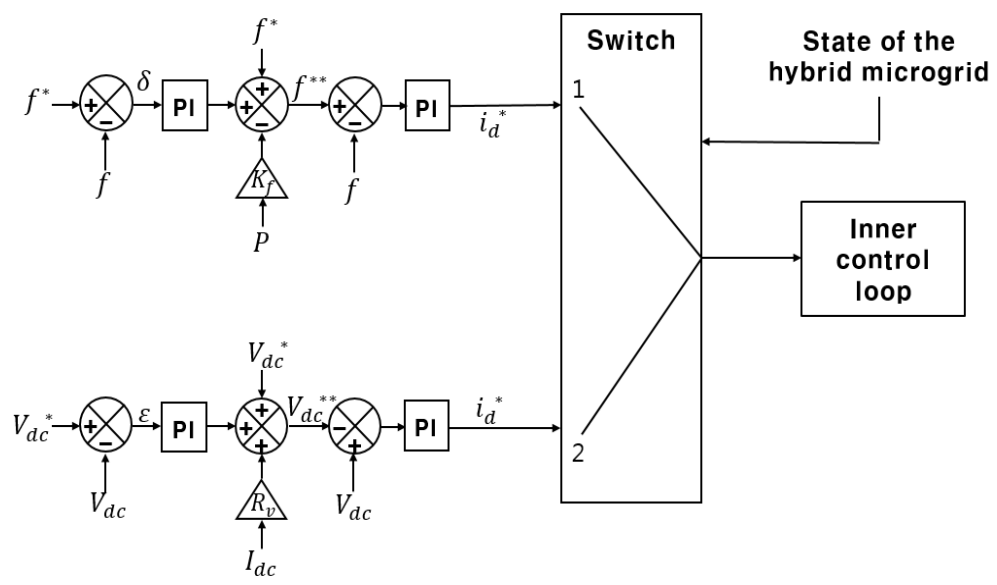

Figure 5. Control Block Diagram of the Interlinking Converter 


\section{Simulation Results}

In this study, various simulation scenarios shown in Table 2 are used to test the performance of proposed control scheme. In three cases, hybrid microgrid is operated in islanded mode at $5 \mathrm{~s}$.

Table 2. Simulation Scenarios

\begin{tabular}{|c|c|}
\hline Case & State of the hybrid microgrid \\
\hline \hline 1 & Variation of AC load from $120 \mathrm{~kW}$ to $180 \mathrm{~kW}$ at $15 \mathrm{~s}$, DC Load $30 \mathrm{~kW}$ \\
\hline 2 & Variation of DC load from $60 \mathrm{~kW}$ to $90 \mathrm{~kW}$ at $15 \mathrm{~s}$, AC Load $100 \mathrm{~kW}$ \\
\hline 3 & $\begin{array}{r}\text { Variation of AC load from } 120 \mathrm{~kW} \text { to } 180 \mathrm{~kW} \text { at } 15 \mathrm{~s} \\
\text { Variation of DC load from } 30 \mathrm{~kW} \text { to } 50 \mathrm{~kW} \text { at } 25 \mathrm{~s}\end{array}$ \\
\hline
\end{tabular}

\subsection{Case 1: Load Variation in AC grid}

In case 1, the hybrid microgrid is switched to islanded mode at $5 \mathrm{~s}$ and $\mathrm{AC}$ load is changed from $120 \mathrm{~kW}$ to $180 \mathrm{~kW}$ at $15 \mathrm{~s}$. Figure 6 shows the power supply and load of the AC grid. At $5 \mathrm{~s}$, the hybrid microgrid is switched to islanded mode and two BESSs are operated based on improved frequency droop control. The AC load increased at $15 \mathrm{~s}$ leads to the lack of power supply in AC grid. Therefore, the power from the DC grid is transferred to the $\mathrm{AC}$ grid by interlinking converter based on improved frequency droop control. Figure 7 shows the power supply and load of DC grid. After increasing AC load, two controllable DC sources generates more power and this power is transferred to AC grid through the interlinking converter. Consequently, the frequency and DC voltage, which are maintained stably at $60 \mathrm{~Hz}$ and $800 \mathrm{~V}$, respectively, are shown in Figure 8.

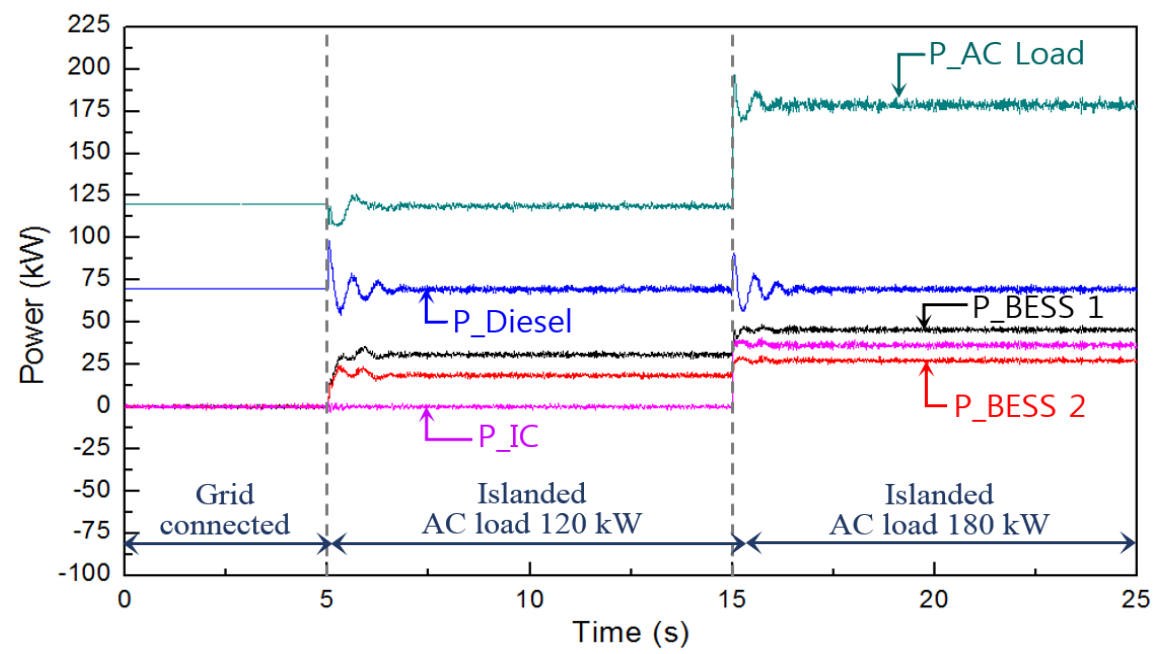

Figure 6. Power in AC Grid 


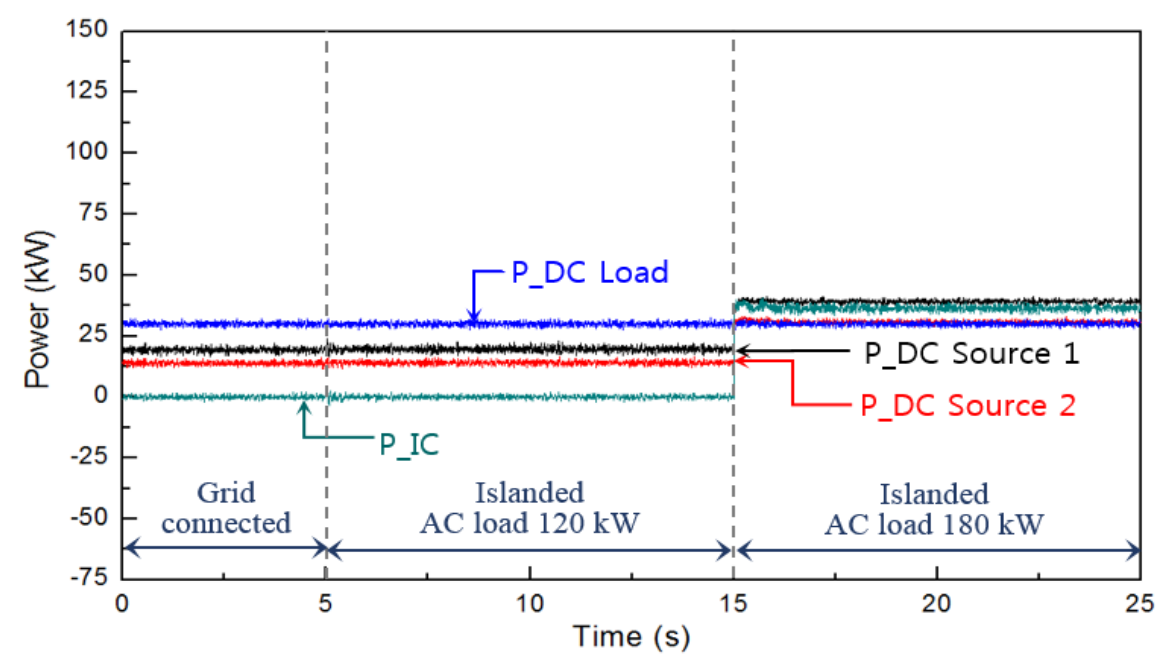

Figure 7. Power in DC Grid

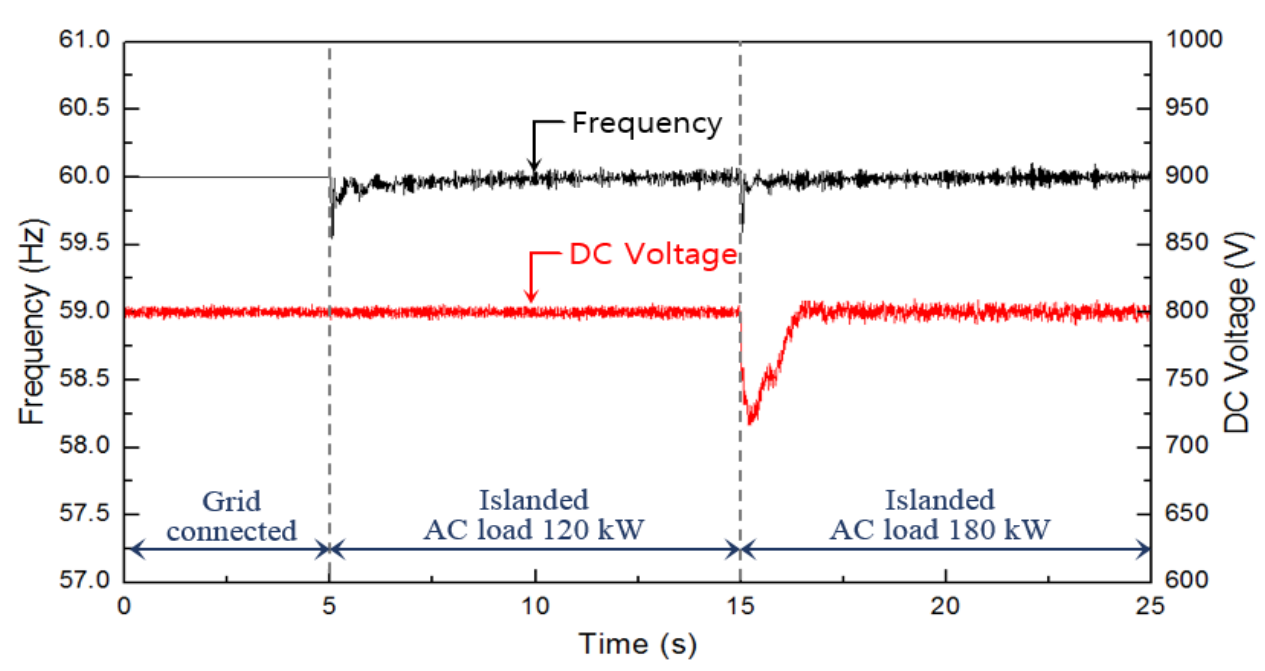

Figure 8. Frequency and DC voltage in the hybrid microgrid

\subsection{Case 2: Load Variation in DC grid}

In case 2, the hybrid microgrid is switched to islanded mode at $5 \mathrm{~s}$ and DC load is changed from $60 \mathrm{~kW}$ to $90 \mathrm{~kW}$ at $15 \mathrm{~s}$. Figure 9 shows the power supply and load of the AC grid. At 5s, the hybrid microgrid is switched to islanded mode and two controllable DC sources are operated based on improved DC voltage droop control. The DC load increased at $15 \mathrm{~s}$ leads to the lack of power supply in DC grid. Therefore, the power from the AC grid is transferred to the DC grid by interlinking converter based on improved DC voltage droop control. Figure 10 shows the power supply and load of DC grid. After increasing DC load, the power is transferred to DC grid through the interlinking converter. Consequently, the frequency and DC voltage, which are maintained stably at $60 \mathrm{~Hz}$ and $800 \mathrm{~V}$, respectively, are shown in Figure 11. 


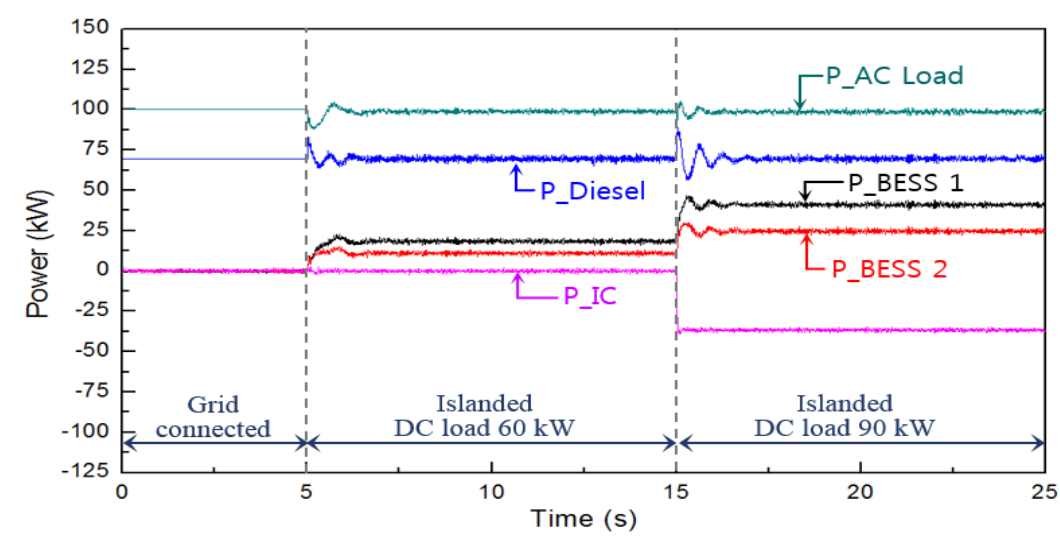

Figure 9. Power in AC Grid

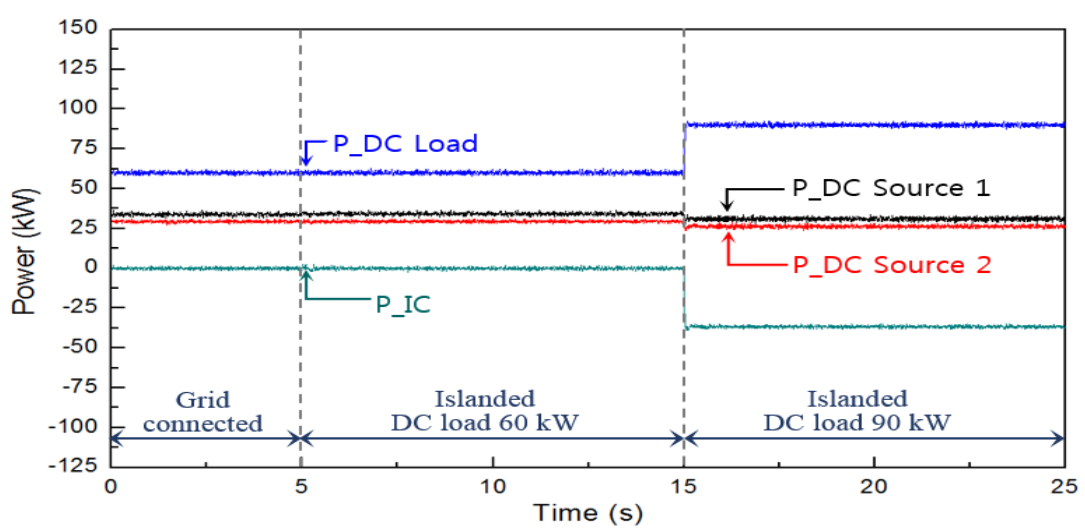

Figure 10. Power in DC Grid

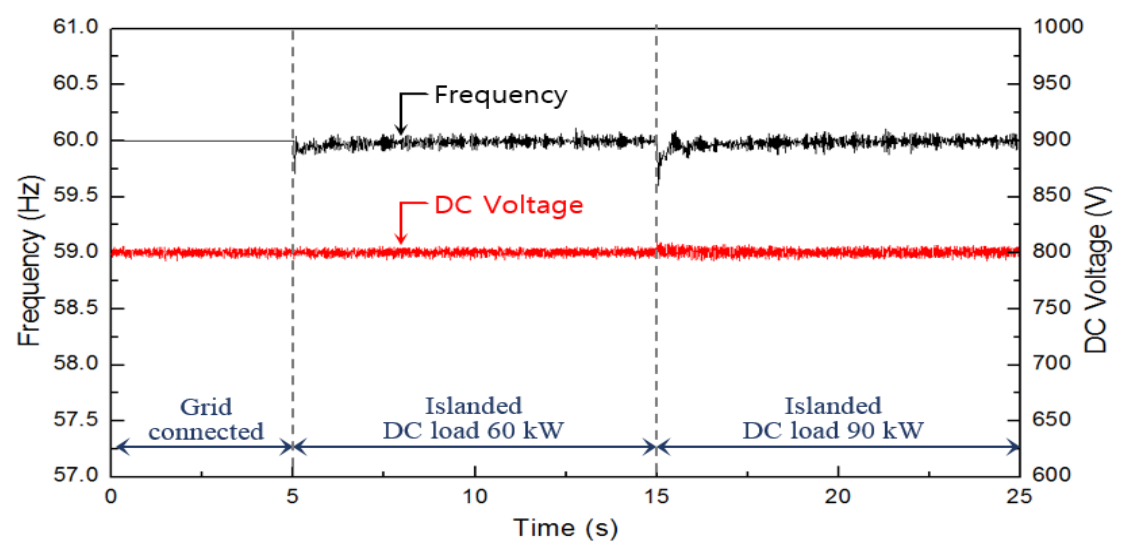

Figure 8. Frequency and DC Voltage in the Hybrid Microgrid

\subsection{Case 3: Overload in the Hybrid Microgrid}

In case 3 , the hybrid microgrid is switched to islanded mode at $5 \mathrm{~s}, \mathrm{AC}$ load is changed from $120 \mathrm{~kW}$ to $18 \mathrm{~kW}$ at $15 \mathrm{~s}$, and DC load is changed from $30 \mathrm{~kW}$ to $50 \mathrm{~kW}$ at $25 \mathrm{~s}$. Figure 12 shows the power supply and load of the AC grid. At $5 \mathrm{~s}$, the hybrid microgrid is switched to islanded mode and two BESSs are operated based on improved frequency droop control. At 15s, after increasing AC load, the power from the DC grid is transferred to the AC grid by interlinking converter based on improved frequency droop control. DC load is increased at $25 \mathrm{~s}$ followed by the shortage power in the hybrid microgrid. Figure 13 shows power supply and load of the DC grid. Two controllable DC sources generate more output power because the AC load is increased at $15 \mathrm{~s}$. In addition, the DC load 
increased at $25 \mathrm{~s}$ leads to shortage power in hybrid microgrid. Therefore, in order to maintain stably frequency and DC voltage, the load in hybrid microgrid is shed at $25.5 \mathrm{~s}$, as shown in Figure 14.

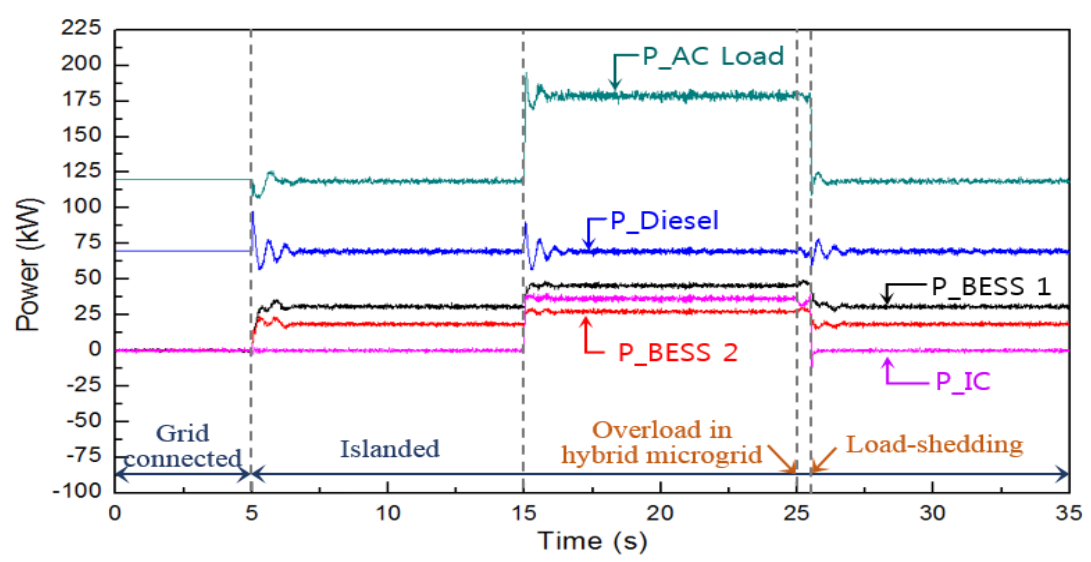

Figure 12. Power in AC Grid

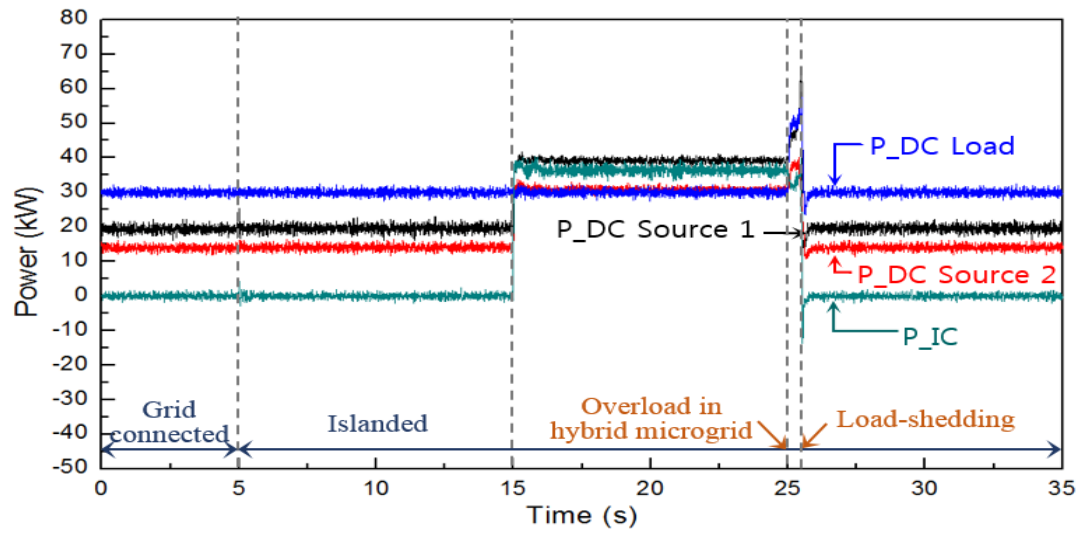

Figure 13. Power in DC Grid

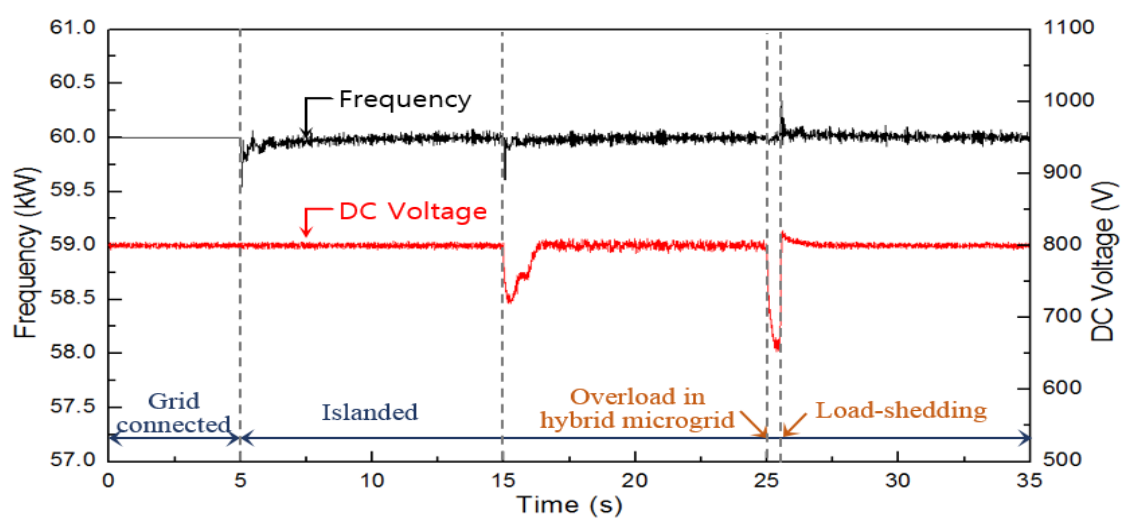

Figure 14. Frequency and DC Voltage in the Hybrid Microgrid

\section{Conclusion}

In this study, the improved droop control scheme was proposed to control frequency and DC voltage of the hybrid microgrid. The control performance of the hybrid microgrid was tested using MATLAB/Simulink. From simulation results, it was found that frequency and DC voltage of hybrid microgrid are maintained stably by using proposed 
control scheme. Depending on the load variation, the control system of interlinking converter was switched to frequency or DC voltage control. For example, when AC load was larger than power supply of the AC grid, the improved frequency droop control was applied to interlinking converter to transfer active power from the DC grid to the AC grid. Besides, when DC load was larger than power supply of the DC grid, the improved DC voltage droop control was applied to interlinking converter to transfer active power from the AC grid to the DC grid. Moreover, when the total load of the hybrid microgrid was larger than total power supply of the hybrid microgrid, the load in hybrid microgrid was shed to maintain stably frequency and DC voltage.

\section{Acknowledgements}

This work was supported by the Power supply \& Electricity Delivery Core Technology Program of the Korea Institute of Energy Technology Evaluation and Planning (KETEP), granted financial resource from the Ministry of Trade, Industry \& Energy, Republic of Korea. (No. 20141020402350).

\section{References}

[1] T. T. Nguyen, H. J. Yoo and H. M. Kim, "A Flywheel Energy Storage System Based on a Doubly Fed Induction Machine and Battery for Microgrid Control”, Energies, vol. 8, no. 6, (2015), pp. 5074-5089.

[2] H. M. Kim, Y. Lim and T. Kinoshita, "An Intelligent Multiagent System for Autonomous Microgrid Operation”, Energies, vol. 5, no. 9, (2012), pp. 3347-3362.

[3] H. M. Kim, and T. Kinoshita, "A Multiagent System for Microgrid Operation in the Grid-interconnected Mode", Journal of Electrical Engineering \& Technology, vol. 5, no. 2, (2010), pp. 246-254.

[4] D. Salomonsson and A. Sannino, "Low-Voltage DC Distribution System for Commercial Power Systems with Sensitive Electronic Loads”, IEEE Transactions on Power Delivery, vol. 22, no. 3 (2007), pp. 1620-1627.

[5] S. Grillo, V. Musolino, L. Piegari, E. Tironi and C. Tornelli, "DC Islands in AC Smart Grids", IEEE Transactions on Power Electronics, vol. 29, no. 1, (2014), pp. 89-98.

[6] J. J. Justo, F. Mwasilu, J. Lee, J. W. Jung, “AC-microgrid versus DC-microgrid with distributed energy resources: A review", Renewable and Sustainable Energy Review, vol. 24, (2013), pp. 387-405.

[7] K. Kurohane, T. Senjyu, A. Yona, N. Urasaki, T. Goya and T. Funabashi, "A hybrid smart AC/DC power system”, IEEE Transactions on Smart Grid, vol. 1, no. 2, (2014), pp. 199-204.

[8] P. C. Loh, D. Li, Y. K. Chai and F. Blaabjerg, "Autonomous Control of Interlinking Converter With Energy Storage in Hybrid AC-DC Microgrid," IEEE Transactions on Industry Application, vol. 49, no. 3, (2013), pp. 1374-1382

[9] P. C. Loh, D. Li, Y. K. Chai and F. Blaabjerg, "Autonomous Operation of Hybrid Microgrid with AC and DC Subgrids", IEEE Transactions on Power Electron, vol. 28, no. 5, (2013), pp. 2214-2223.

[10] R. Majumder, "A Hybrid Microgrid With DC Connection at Back to Back Converters", IEEE Transactions on Smart Grid, vol. 5, no. 1, (2014), pp. 251-259.

[11] X. Liu, P. Wang, and P. C. Loh, "A Hybrid AC/DC Microgrid and Its Coordination Control”, IEEE Transactions on Smart Grid, vol. 2, no. 2, (2013), pp. 278-286.

[12] C. Wang, X. Li, L. Guo and Y. W. Li, "A Nonlinear-Disturbance-Observer-Based DC-Bus Voltage Control for a Hybrid AC/DC Microgrid”, IEEE Transactions on Power Electronics, vol. 29, no. 11, (2014), pp. 6162-6177.

[13] N. Eghtedarpour and E. Farjah, "Power Control and Management in a Hybrid AC/DC Microgrid," IEEE Transactions on Smart Grid, vol. 5, no. 3, (2014), pp. 1494-1505.

[14] H.-K. Ji, T.-T. Nguyen, H.-I. Son and H.-M. Kim, "A Control Structure for Bidirectional Converter of Hybrid AC/DC Microgrid in the Islanded Mode", International Conference on Smart Technologies for Energy, Information and Communication, (2014).

[15] W. Choi, J. B. Baek and B. H. Cho, "Control design of coordinated droop control for hybrid AC/DC microgrid considering distributed generation characteristics", Energy Conversion Congress and Exposition, (2014), pp. 4276-4281.

[16] J. He and Y. W. Li, "An Enhanced Microgrid Load Demand Sharing Strategy", IEEE Transactions on Power Electronics, vol. 27, no. 9, (2012), pp. 3984-3995. 

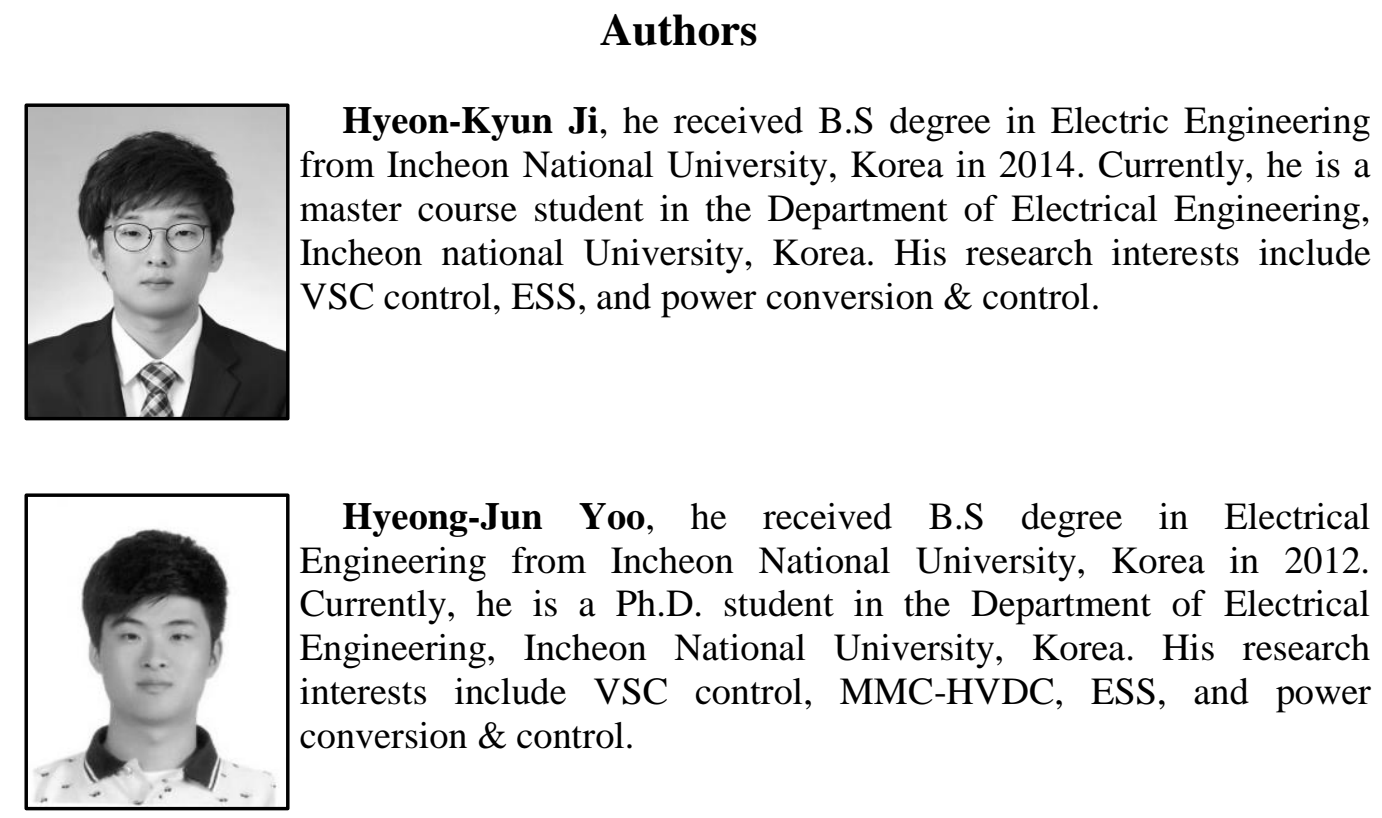

Hyeong-Jun Yoo, he received B.S degree in Electrical Engineering from Incheon National University, Korea in 2012. Currently, he is a Ph.D. student in the Department of Electrical Engineering, Incheon National University, Korea. His research interests include VSC control, MMC-HVDC, ESS, and power conversion \& control.

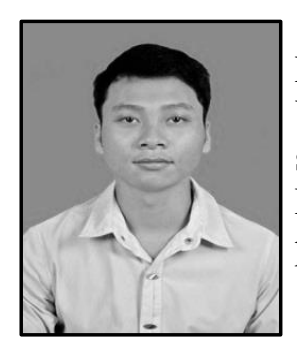

Thai-Thanh Nguyen, he received his B.S degree in Electrical Engineering from Hanoi University of Science and Technology, Vietnam, in 2013. Currently, he is a combined Master and Ph.D. student in the Department of Electrical Engineering, Incheon National University, Korea. His research interests include microgrids, power system analysis \& modeling, FACTS, and HVDC.

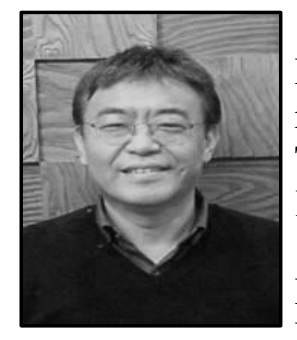

Hak-Man Kim, he received his first Ph.D. degree in Electrical Engineering from Sungkyunkwan University, Korea in 1998 and received his second $\mathrm{Ph}$. D. degree in Information Sciences from Tohoku University, Japan, in 2011, respectively. He worked for Korea Electrotechnology Research Institute (KERI), Korea from Oct. 1996 to Feb. 2008. Currently, he is a professor in the Department of Electrical Engineering and also serves as the Vice Dean of College of Engineering, Incheon National University, Korea. His research interests include power system analysis \& modeling, HVDC, FACTS, microgrids, and LVDC. 